\title{
Dosing of Intravenous Tocilizumab in a Real-World Setting of Rheumatoid Arthritis: Analyses from the Corrona Registry
}

\author{
Dimitrios A. Pappas · Ani John · Jeffrey R. Curtis · George W. Reed • \\ Chitra Karki · Robert Magner · Joel M. Kremer • Ashwini Shewade • \\ Jeffrey D. Greenberg
}

Received: December 2, 2015 / Published online: February 8, 2016

(c) The Author(s) 2016. This article is published with open access at Springerlink.com

\section{ABSTRACT}

Introduction: In the United States, the recommended starting dose of intravenous tocilizumab (TCZ) is $4 \mathrm{mg} / \mathrm{kg}$ every 4 weeks, with an increase to $8 \mathrm{mg} / \mathrm{kg}$ based on clinical response for patients with moderate to severe

Electronic supplementary material The online version of this article (doi:10.1007/s40744-016-0028-0) contains supplementary material, which is available to authorized users.

D. A. Pappas $(\square)$

Columbia University, New York, NY, USA

e-mail: dpappas@corrona.org

A. John · A. Shewade

Genentech, Inc, South San Francisco, CA, USA

J. R. Curtis

University of Alabama at Birmingham, Birmingham,

$\mathrm{AL}$, USA

G. W. Reed · C. Karki · J. D. Greenberg

Corrona, LLC, Southborough, MA, USA

G. W. Reed · R. Magner

University of Massachusetts Medical School,

Worcester, MA, USA

J. M. Kremer

Albany Medical College and The Center for

Rheumatology, Albany, NY, USA

J. D. Greenberg

NYU School of Medicine, New York, NY, USA rheumatoid arthritis; however, data on how TCZ dose is escalated in real life are missing. The objective of this analysis was to describe patterns of early intravenous TCZ dose escalation in a real-world setting using data from the Corrona registry.

Methods: All patients enrolled in the comparative effectiveness substudy (CERTAIN) nested within Corrona who initiated TCZ and completed 3- and 6-month study visits were eligible for inclusion. Patients who initiated TCZ $4 \mathrm{mg} / \mathrm{kg}$ were categorized into 1 of 2 groups: those who remained on TCZ $4 \mathrm{mg} / \mathrm{kg}$ at 3 months (Group 1) and those who escalated to TCZ $8 \mathrm{mg} / \mathrm{kg}$ by or at 3 months (Group 2). Changes in clinical disease activity measures were provided.

Results: Of the 213 patients who were eligible for analysis, 86 (40.4\%) remained on their initial dose of TCZ $4 \mathrm{mg} / \mathrm{kg}$ (Group 1) and 110 (51.6\%) were escalated to TCZ $8 \mathrm{mg} / \mathrm{kg}$ by or at 3 months (Group 2). Baseline demographic and clinical characteristics were similar between the 2 groups; except in Group 2, patients were older (58.3 vs. 54.0 years) and a lower proportion was female $(75.5 \%$ vs. $89.4 \%)$ than in Group 1. Significant improvements in disease activity 
measures were observed at 3 and 6 months in both groups, with the majority of patients in both groups achieving moderate or good European League Against Rheumatism response.

Conclusion: Real-world data demonstrated that physicians escalate TCZ dose at varying frequencies. The ability to administer TCZ in varying doses allows physicians to tailor TCZ therapy to disease activity.

Trial registration: ClinicalTrials.gov identifier, NCT01625650.

Keywords: Biologic agents; Disease-modifying antirheumatic drugs; Prescribing patterns; Registry; Rheumatoid arthritis; Tocilizumab

\section{INTRODUCTION}

Rheumatoid arthritis (RA) is a chronic autoimmune inflammatory disorder of the joints that, if left untreated, leads to joint damage and disability. Conventional synthetic disease-modifying antirheumatic drugs (csDMARDs) are recommended as first-line therapy for patients with RA, with the goal of achieving remission or low disease activity [1, 2]. However, a proportion of patients fail to achieve this goal with csDMARDs alone, and the addition of or switch to a biologic DMARD, such as tocilizumab (TCZ), may provide increased efficacy $[1,2]$.

Tocilizumab is the first approved drug for RA that inhibits the interleukin 6 (IL-6) receptor alpha. TCZ is approved for the treatment of patients with moderate to severe active RA who have had an inadequate response to one or more DMARDs [3]. TCZ has been approved to be used in combination with csDMARDs or as monotherapy, making it an attractive therapy for patients who cannot tolerate csDMARDs
[4-7]. In addition, intravenous TCZ can be administered in 2 different doses ( 4 and $8 \mathrm{mg}$ / $\mathrm{kg}$ ) and adjusted to the individual patient's disease activity.

The recommended dosing regimen of intravenous TCZ varies around the world. In European countries and Japan, the recommended starting dose of TCZ is $8 \mathrm{mg} / \mathrm{kg}$ every 4 weeks. In the United States (US), the recommended starting dose of intravenous TCZ for patients with moderate to severe RA, either as in combination with csDMARDs or as a monotherapy, is $4 \mathrm{mg} / \mathrm{kg}$ every 4 weeks. The dose may be increased to $8 \mathrm{mg} / \mathrm{kg}$ based on clinical response, at the physician's discretion [3]. Data from clinical trials have shown significant efficacy with both the 4- and 8-mg/ $\mathrm{kg}$ doses of TCZ in patients with RA [8-13]. Overall, patients were more likely to achieve better disease activity responses with TCZ $8 \mathrm{mg}$ / $\mathrm{kg}$ than with TCZ $4 \mathrm{mg} / \mathrm{kg}$, but individual responses varied [8-13]. In real-world settings in the US, the option to change the dose of TCZ based on clinical response allows physicians to tailor the treatment dose to the disease activity; however, data on dose escalation in everyday practice are limited. This descriptive analysis provides data on dosing patterns in the US, where there is higher variability in TCZ dosing than in other countries.

The objective of this analysis was to describe the patterns of intravenous TCZ dose escalation in a real-world clinical setting over 6 months of therapy using data from a large, observational US patient registry (Corrona). Descriptive data showing changes in clinical disease activity, functional status, and inflammatory markers at 3 and 6 months after therapy with different dose escalation patterns of TCZ were also provided. 


\section{METHODS}

\section{Corrona Study Population}

Patients enrolled in the Corrona registry and participating in the CERTAIN (Comparative Effectiveness Registry to Study Therapies for Arthritis and Inflammatory Conditions) substudy were included in this analysis. The Corrona registry is an independent, prospective observational cohort of patients with RA. Details of the Corrona registry design have been previously described [14].

\section{CERTAIN Substudy}

The CERTAIN study (ClinicalTrials.gov identifier, NCT01625650) was nested within Corrona and was designed to investigate comparative effectiveness and comparative safety of approved biologics for the treatment of RA [15]. CERTAIN included 43 sites involving $>100$ physicians. For enrollment into CERTAIN, patients $\geq 18$ years of age were required to have moderate or high RA disease activity, defined as Clinical Disease Activity Index (CDAI) $>10$, and have had a first-time initiation of a biologic agent for the treatment of RA. All procedures followed were in accordance with the ethical standards of the responsible committee on human experimentation (institutional and national) and with the Helsinki Declaration of 1964, as revised in 2013. All patients in CERTAIN provided written informed consent for participation. The protocol was approved by the institutional review boards of participating academic sites and a central institutional review board for private practice sites.

A total of 2358 patients were enrolled and had $\geq 1$ biologic initiation. The decision to start a particular biologic and offer patient enrollment in CERTAIN was at the discretion of the treating physician; patients were not randomized. Patients were enrolled in the study at the time of biologic initiation and were followed every 3 months until completion of 12 months of follow-up, unless they switched or discontinued the biologic earlier. Patient enrollment in the CERTAIN study was completed on April 30, 2014. Upon completion of participation in CERTAIN, patients were rolled over to the main Corrona RA registry for long-term safety follow-up.

\section{Study Population}

This analysis was restricted to those patients enrolled in CERTAIN who initiated intravenous TCZ between November 11, 2010 and August 29, 2013 and for whom 3- and 6-month follow-up data were available by March 2014 . There were 138 patients who did not have a visit beyond 3 months and were not included in this analysis. Of these, 4 patients were excluded at baseline, 54 patients did not have the opportunity to have a 3- and 6-month follow-up visit, and 80 patients exited CERTAIN prior to their 6-month visit. Among patients who exited CERTAIN early, 63 patients discontinued TCZ prior to the 6-month visit and 15 patients withdrew from the study without stopping treatment.

\section{Statistical Analysis}

Patients were categorized in separate dosing pattern groups based on TCZ dose information collected at baseline, 3 and 6 months. Data were analyzed from patients who started TCZ therapy at $4 \mathrm{mg} / \mathrm{kg}$ and either remained on their initial TCZ dose of $4 \mathrm{mg} / \mathrm{kg}$ at 3 months (Group 1) or had their initial TCZ dose of $4 \mathrm{mg} / \mathrm{kg}$ escalated to TCZ $8 \mathrm{mg} / \mathrm{kg}$ by or at 3 months (Group 2). Patients who had their dose escalated after 3 months were 
included in Group 1 for this analysis. Patients who started TCZ at a dose of $8 \mathrm{mg} / \mathrm{kg}$ or who increased and subsequently decreased the TCZ dose were categorized in a separate group (Group 3). Patients who discontinued TCZ for any reason prior to the 6-month follow-up visit were not included in this analysis.

Study questionnaires were designed to capture whether any changes in TCZ dose occurred between visits; however, exact dates of dose changes were not captured unless the change in TCZ dose occurred at the time of the CERTAIN follow-up visit.

Clinical data were collected in CERTAIN for patients at baseline and at 3, 6, 9, and 12 months; however, for this analysis, data were restricted to those collected at 3 and 6 months due to the low number of patients who had data beyond 6 months. These assessments included Disease Activity Score in 28 joints using C-reactive protein (DAS28-CRP), CDAI, CRP, modified Health Assessment Questionnaire (mHAQ), patient pain, patient fatigue, and European League Against Rheumatism (EULAR) response. Clinical disease activity levels at 3 and 6 months for the 2 dosing pattern groups were calculated and included the proportion of patients in each group who achieved remission (CDAI $\leq 2.8$ ) or low disease activity (CDAI $\leq 10)$, the minimal clinically important difference (MCID) for CDAI, DAS28-CRP remission (DAS28-CRP <2.32), DAS28-CRP low disease activity (DAS28-CRP <2.67), and EULAR responses (good, moderate, or no response) at 3 and 6 months. The MCID was defined as a decrease in CDAI of $\geq 6$ in patients with a baseline CDAI between 10 and 22 (moderate disease activity) and as a decrease in CDAI of $\geq 11$ in patients with a baseline CDAI $>22$ (high disease activity) [16]. Other measures included the median change from baseline in CDAI, DAS28-CRP,
CRP, patient pain, patient fatigue, and mHAQ scores at 3 and 6 months.

\section{RESULTS}

\section{TCZ Dosing Patterns}

As of August 29, 2013, there were a total of 213 patients eligible for inclusion in this analysis; 199 patients (93.4\%) initiated TCZ at $4 \mathrm{mg} / \mathrm{kg}$ and 14 patients (6.6\%) initiated TCZ at $8 \mathrm{mg} / \mathrm{kg}$ (Fig. 1). Among the 199 patients who initiated TCZ at $4 \mathrm{mg} / \mathrm{kg}, \quad 86 \quad(40.3 \%$ of the total population) were escalated to TCZ $8 \mathrm{mg} / \mathrm{kg}$ after the 3-month visit and by the 6-month follow-up visit (Group 1), and 110 (51.6\% of the total population) were escalated to TCZ $8 \mathrm{mg} / \mathrm{kg}$ by or at 3 months and remained on this dose during the observation period (Group 2). The remaining patients (Group 3) consisted of three individuals whose TCZ dose was escalated from 4 to $8 \mathrm{mg} / \mathrm{kg}$ at 3 months before it was returned to $4 \mathrm{mg} / \mathrm{kg}$ at 6 months, and an additional 14 who initiated TCZ at $8 \mathrm{mg} / \mathrm{kg}$ and were thus unable to have their treatment escalated (Fig. 1). These patients were excluded from further analysis due to the small sample size.

Within Group 1, 45 patients remained on their initial TCZ dose of $4 \mathrm{mg} / \mathrm{kg}$ through 6 months and 41 patients had their TCZ dose escalated to $8 \mathrm{mg} / \mathrm{kg}$ by 6 months (i.e., any time after the 3-month visit and prior to the 6-month visit). Within Group 2, 82 patients had their dose escalated prior to the 3-month visit and 28 patients had their dose escalated at the time of the 3-month visit.

\section{Baseline Characteristics}

The majority of the 213 patients eligible for analysis were female and white, with a median age of 56.5 years (Table 1). At baseline, patients 
Fig. 1 Summary of patient distribution by TCZ dosing patterns over the first 6 months of therapy. Orange circles represent the administration of a TCZ dose of $4 \mathrm{mg} / \mathrm{kg}$ at the specified visit and blue circles represent a TCZ dose of $8 \mathrm{mg} /$ kg. TCZ Tocilizumab

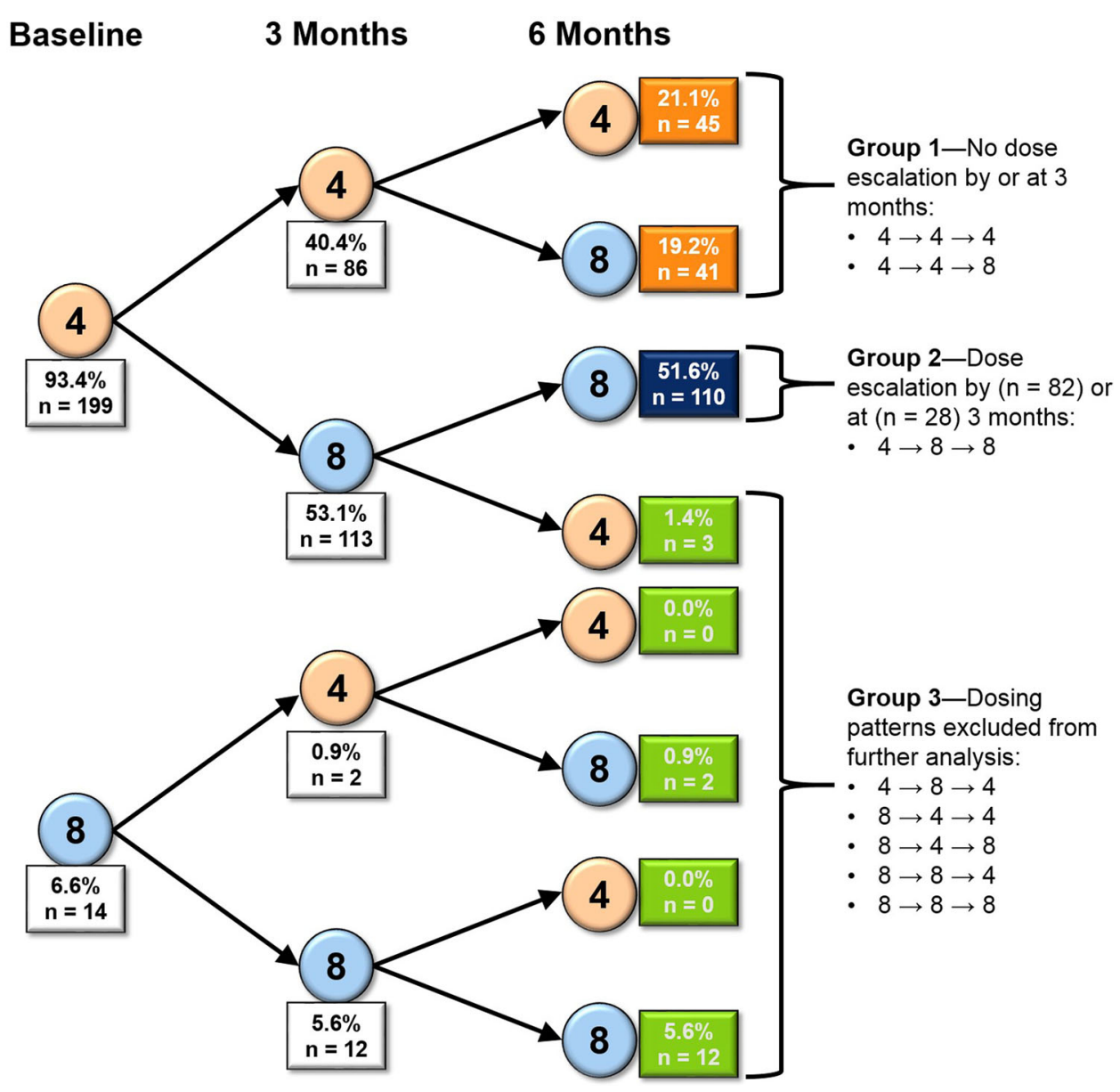

had established, advanced disease, with a median disease duration of 11.2 years, a median CDAI of 31.8 , and a median mHAQ score of 0.6. Most patients (95.8\%) had previous exposure to biologics (median, 2.0 prior biologics). Baseline patient demographic and clinical characteristics for the 2 dosing groups (Group 1 and Group 2) were mostly similar (Tables 2, 3). Patients in both groups had similar mean (SD) duration of RA [10.9 (8.7) years and 11.6 (8.9) years for Groups 1 and 2, respectively] and high mean baseline disease activity (Table 2), and the majority had a history of multiple biologic DMARD treatment failures prior to initiation of TCZ (Table 3). Patients in Group 1 were younger in age (mean, 54.0 vs. 58.3 years) and a higher proportion were female $(89.4 \%$ vs. $75.5 \%)$ compared with patients in Group 2. Approximately $30 \%$ of patients received TCZ as monotherapy and 50\% of patients received concomitant methotrexate and the proportions of patients receiving concomitant csDMARDs were similar between the dosing groups (Table 3).

\section{Disease Activity, Functional Status, and CRP at 3 and 6 Months in Patients Who Did Not Escalate TCZ Dose by 3 Months (Group 1)}

Of the patients who continued to receive TCZ $4 \mathrm{mg} / \mathrm{kg}$ at 3 months (Group 1), at 3 and 6 months, respectively, $62 \%$ and $68 \%$ had 
Table 1 Baseline demographic and clinical characteristics for all eligible patients

\begin{tabular}{ll}
\hline Characteristics & $\begin{array}{l}\text { All eligible patients } \\
(\boldsymbol{N}=\mathbf{2 1 3})\end{array}$ \\
\hline Age, mean (SD), years & $56.5(12.9)$ \\
Female, \% & 82.1 \\
White, \% & 86.4 \\
Duration of RA, mean (SD), years & $11.2(8.7)$ \\
Weight, mean (SD), kg & $84.3(22.3)$ \\
RF or ACPA seropositive, \% & 58.7 \\
CDAI, mean (SD) & $31.8(13.3)$ \\
DAS28-CRP, mean (SD) & $5.0(1.1)$ \\
CRP, mean (SD), mg/L & $11.4(17.4)$ \\
Patient pain, mean (SD) & $58.2(24.5)$ \\
Patient fatigue, mean (SD) & $59.6(27.6)$ \\
mHAQ, mean (SD) & $0.6(0.6)$ \\
HAQ-DI, mean (SD) & $1.2(0.7)$ \\
Biologic naive, \% & 4.2 \\
No. of prior biologics, & $2.0(1.0-3.0)$ \\
median (IQR) & \\
\hline
\end{tabular}

$A C P A$ Anti-cyclic citrullinated peptide antibody, $C D A I$ Clinical Disease Activity Index, CRP C-reactive protein, $D A S 28$-CRP Disease Activity Score in 28 joints using CRP, HAQ-DI Health Assessment Questionnaire Disability Index, IQR Interquartile range, $m H A Q$ Modified Health Assessment Questionnaire, RA Rheumatoid arthritis, $R F$ Rheumatoid factor

achieved an MCID based on CDAI, 40\% and $45 \%$ had achieved DAS28-CRP low disease activity or remission, and $57 \%$ and $65 \%$ had achieved a moderate or good EULAR response (Fig. 2a). In addition, patients in Group 1 exhibited decreases in all disease activity measures (CDAI, DAS28-CRP, pain, fatigue, and (CRP) at 3 and 6 months from baseline (Fig. 2b). The median (interquartile range [IQR]) decrease from baseline in mHAQ at 3 and 6 months was $0.0(-0.3$ to 0.0$)$ and $0.0(-0.3$ to 0.0 ), respectively, for patients in Group 1 (not shown).

\section{Disease Activity, Functional Status, and CRP at 3 and 6 Months in Patients Who Escalated TCZ Dose by or at 3 Months (Group 2)}

Of the patients who escalated to TCZ $8 \mathrm{mg} / \mathrm{kg}$ by or at 3 months (Group 2), at 3 and 6 months, respectively, $55 \%$ and $67 \%$ had achieved an MCID based on CDAI, 50\% and 67\% had achieved DAS28-CRP low disease activity or remission, and 59\% and $66 \%$ had achieved a moderate or good EULAR response (Fig. 3a). Similar to patients in Group 1, patients in Group 2 exhibited decreases in all disease activity measures (CDAI, DAS28-CRP, pain, fatigue, and CRP) at 3 and 6 months from baseline (Fig. 3b). The median (IQR) decrease from baseline in mHAQ at 3 and 6 months was 0.0 ( -0.3 to 0.0$)$ and 0.0 ( -0.4 to 0.0 ), respectively, for patients in Group 2 (not shown).

\section{DISCUSSION}

This study, among the first to describe how TCZ dose is being escalated in real-world settings in the US, found that most patients have their dose escalated within 6 months of initiation. Patients in the US generally initiate TCZ at $4 \mathrm{mg} / \mathrm{kg}$, and physicians have the choice whether and when to escalate the dose to $8 \mathrm{mg} / \mathrm{kg}$. Data from this group of patients from the CERTAIN study demonstrated that US physicians escalate the dose of TCZ at varying frequencies, with favorable results in terms of response of disease activity and other effectiveness measures, including patient-reported outcomes. Of the 213 patients 
Table 2 Baseline demographic and clinical characteristics by dose escalation group

\begin{tabular}{lll}
\hline Characteristics & $\begin{array}{l}\text { Group 1: No dose escalation } \\
\text { by or at } 3 \text { months }(\boldsymbol{n}=\mathbf{8 6})\end{array}$ & $\begin{array}{l}\text { Group 2: Dose escalation by or } \\
\text { at } 3 \text { months }(\boldsymbol{n}=\mathbf{1 1 0})\end{array}$ \\
\hline Age, mean (SD), years ${ }^{\mathrm{a}}$ & $54.0(11.8)$ & $58.3(13.4)$ \\
Female, \% $^{\mathrm{a}}$ & 89.4 & 75.5 \\
White, \% & 81.4 & 90.0 \\
Duration of RA, mean (SD), years & $10.9(8.7)$ & $11.6(8.9)$ \\
Weight, mean (SD), kg & $86.2(22.4)$ & $83.7(22.8)$ \\
RF or ACPA seropositive, \% & 55.4 & 58.4 \\
CDAI, mean (SD) & $32.4(13.9)$ & $31.3(12.9)$ \\
DAS28-CRP, mean (SD) & $5.1(1.1)$ & $5.0(1.2)$ \\
CRP, mean (SD), mg/L & $10.4(15.1)$ & $13.0(20.2)$ \\
Patient pain, mean (SD) & $57.4(23.8)$ & $58.6(24.4)$ \\
Patient fatigue, mean (SD) & $59.2(28.6)$ & $58.9(27.0)$ \\
mHAQ, mean (SD) & $0.6(0.6)$ & $0.7(0.5)$ \\
HAQ-DI, mean (SD) & $1.2(0.7)$ & $1.2(0.7)$ \\
Biologic naive, \% & 2.3 & 4.6 \\
No. of prior biologics, median (IQR) & $2.0(1.0-4.0)$ & $2.0(1.0-3.0)$ \\
\hline
\end{tabular}

$A C P A$ Anti-cyclic citrullinated peptide antibody, CDAI Clinical Disease Activity Index, CRP C-reactive protein, DAS28-CRP Disease Activity Score in 28 joints using CRP, HAQ-DI Health Assessment Questionnaire Disability Index, $I Q R$ interquartile range, $m H A Q$ Modified Health Assessment Questionnaire, $R A$ Rheumatoid arthritis, $R F$ Rheumatoid factor

a $P<0.05$. $P$ values based on the $t$ test to compare means and the Fisher exact test to compare binary outcomes between dose escalation groups

eligible for this analysis, $93.4 \%$ initiated TCZ at $4 \mathrm{mg} / \mathrm{kg}$, and by 6 months, $77 \%$ of patients were receiving TCZ $8 \mathrm{mg} / \mathrm{kg}$. All of the 14 patients who initiated TCZ at $8 \mathrm{mg} / \mathrm{kg}$ were receiving TCZ $8 \mathrm{mg} / \mathrm{kg}$ at 6 months; 2 of these patients had had their dose decreased by or at 3 months followed by escalation back to TCZ $8 \mathrm{mg} / \mathrm{kg}$ by 6 months. Of the patients who initiated TCZ at $4 \mathrm{mg} / \mathrm{kg}, 57 \%$ had their TCZ dose escalated by or at 3 months, rising to $76 \%$ by 6 months. Baseline disease activity and prior medication history were similar between patients who escalated during the initial 3-month period and patients who did not; however, patients who escalated by or at 3 months were older and more likely to be male. Improvements in all disease activity measures were observed at 3 and 6 months after the initiation of TCZ in both groups of patients.

The patients in this analysis had established disease of long duration, high disease activity at baseline, and failure of other biologic agents prior to therapy with $\mathrm{TCZ}$, indicating a population rather refractory to therapy. In this population, the majority of patients achieved a moderate or good EULAR response regardless of the dosing pattern, complementing the efficacy data of TCZ stemming from clinical trials $[6,9$, 
Table 3 Concomitant medications at baseline by dose escalation group in patients initiating TCZ at $4 \mathrm{mg} / \mathrm{kg}$

\begin{tabular}{lll}
\hline Baseline medications & $\begin{array}{l}\text { Group 1: No dose escalation } \\
\text { by or at } 3 \text { months }(\boldsymbol{n}=\mathbf{8 6})\end{array}$ & $\begin{array}{l}\text { Group 2: Dose escalation by or } \\
\text { at } 3 \text { months }(\boldsymbol{n}=\mathbf{1 1 0})\end{array}$ \\
\hline Currently receiving prednisone, \% & 30.2 & 24.6 \\
$<5 \mathrm{mg} /$ day, \% $(n)$ & $26.9(7)$ & $11.1(3)$ \\
$\geq 5 \mathrm{mg} /$ day, \% $(n)$ & $73.1(19)$ & $88.9(24)$ \\
Prednisone dose, median (IQR), mg/day & $5.0(4.0-10.0)$ & $10.0(5.0-10.0)$ \\
TCZ as monotherapy, \% & 33.7 & 28.2 \\
Receiving concurrent DMARD, \% & 66.3 & 71.8 \\
Methotrexate, \% & 50.0 & 50.0 \\
Leflunomide, \% & 9.3 & 10.0 \\
Sulfasalazine, \% & 2.3 & 4.6 \\
Hydroxychloroquine, \% & 10.5 & 9.1 \\
\hline
\end{tabular}

$D M A R D$ Disease-modifying antirheumatic drug, IQR interquartile range, $T C Z$ tocilizumab

10, 17]. The favorable responses observed in both dosing groups, regardless of whether TCZ was initiated as monotherapy or in combination with csDMARDs, indicate that participating physicians were responding appropriately to disease activity levels, as medication dosing was at their discretion based on the CERTAIN protocol.

Although data directly comparing the 2 doses (4 vs. $8 \mathrm{mg} / \mathrm{kg}$ ) are limited, clinical trials comparing TCZ $4 \mathrm{mg} / \mathrm{kg}$ vs. placebo and TCZ $8 \mathrm{mg} / \mathrm{kg}$ vs. placebo have shown that a higher proportion of patients receiving TCZ $8 \mathrm{mg} / \mathrm{kg}$ achieved ACR responses at 6 months than patients receiving TCZ $4 \mathrm{mg} / \mathrm{kg}[9,10]$. In one trial, a greater reduction in DAS28 was observed with TCZ $8 \mathrm{mg} / \mathrm{kg}$ than with TCZ $4 \mathrm{mg} / \mathrm{kg}$ as early as 4 weeks after initiating therapy [13]. In the present analysis, a large proportion of patients $(76 \%)$ was found to have their dose escalated by their physician within 6 months of initiating treatment, indicating physicians perceived the potential for a large proportion of patients to experience improved clinical response by escalating to TCZ $8 \mathrm{mg} / \mathrm{kg}$ vs. remaining at TCZ $4 \mathrm{mg} / \mathrm{kg}$; however, both groups of patients (those who escalated by or at 3 months and those who did not) exhibited significant improvements in disease activity levels at both 3 and 6 months. These data suggest that in real-world settings, physicians respond to disease activity levels and that the option to adjust TCZ dose based on individual clinical responses may have provided an additional benefit to the patients.

In this study, only $22.6 \%$ of patients remained at the TCZ $4-\mathrm{mg} / \mathrm{kg}$ dose 6 months after initiation of therapy and $1.5 \%$ returned to $4 \mathrm{mg} / \mathrm{kg}$ after an initial increase to $8 \mathrm{mg} / \mathrm{kg}$. While it is likely that dose reductions in these patients were due to safety concerns, previous studies have shown that a sufficient response with TCZ $8 \mathrm{mg} / \mathrm{kg}$ may warrant dose reduction. In a retrospective study of 22 patients with RA who received TCZ $8 \mathrm{mg} / \mathrm{kg}$ for 6 months and had their dose tapered to $4 \mathrm{mg} / \mathrm{kg}$ because of low disease activity, $55 \%$ of patients remained in disease remission 6 months after the dose 


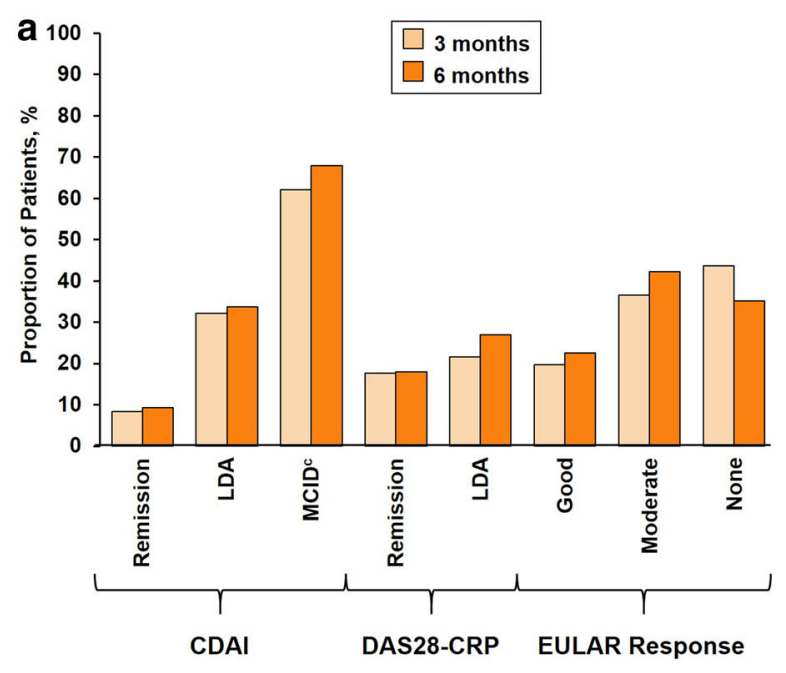

b

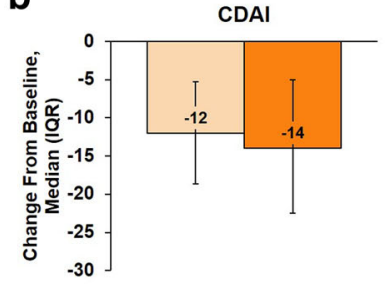

Patient Pain

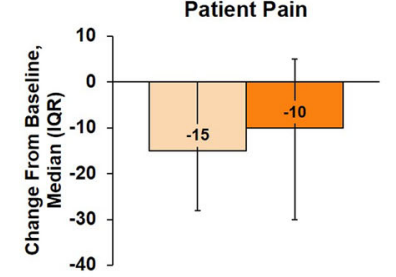

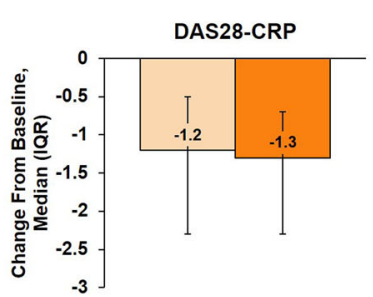

Patient Fatigue

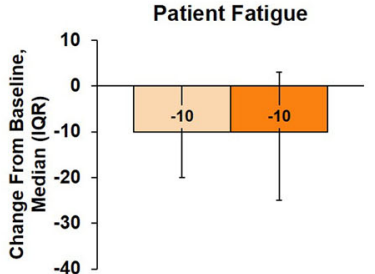

CRP, mg/L

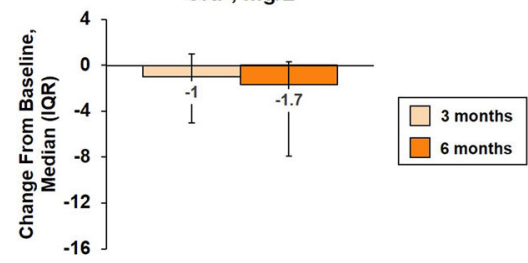

Fig. 2 Disease activity (a) and functional status and CRP (b) of patients in Group $1(n=86)$ at 3 and 6 months. Patients in Group 1 remained on TCZ $4 \mathrm{mg} / \mathrm{kg}$ at 3 months and either did not have their dose escalated by 6 months $(n=45)$ or had it escalated between 3 and 6 months $(n=41)$. Median (IQR) decrease from baseline in mHAQ at 3 months was $0.0(-0.3$ to 0.0$)$ and 0.0 $(-0.3$ to 0.0$)$ for patients in Group 1 and Group 2, respectively. MCID was defined as a decrease in CDAI of $\geq 6$ in patients with a baseline CDAI between 10 and 22 (moderate disease activity) and as a decrease in CDAI of $\geq 11$ in patients with a baseline CDAI $>22$ (high disease activity). $C D A I$ Clinical Disease Activity Index, CRP C-reactive protein, DAS28-CRP Disease Activity Score in 28 joints using CRP, EULAR European League Against Rheumatism, IQR Interquartile range, $L D A$ Low disease activity, $M C I D$ Minimal clinically important difference, mHAQ Modified Health Assessment Questionnaire 

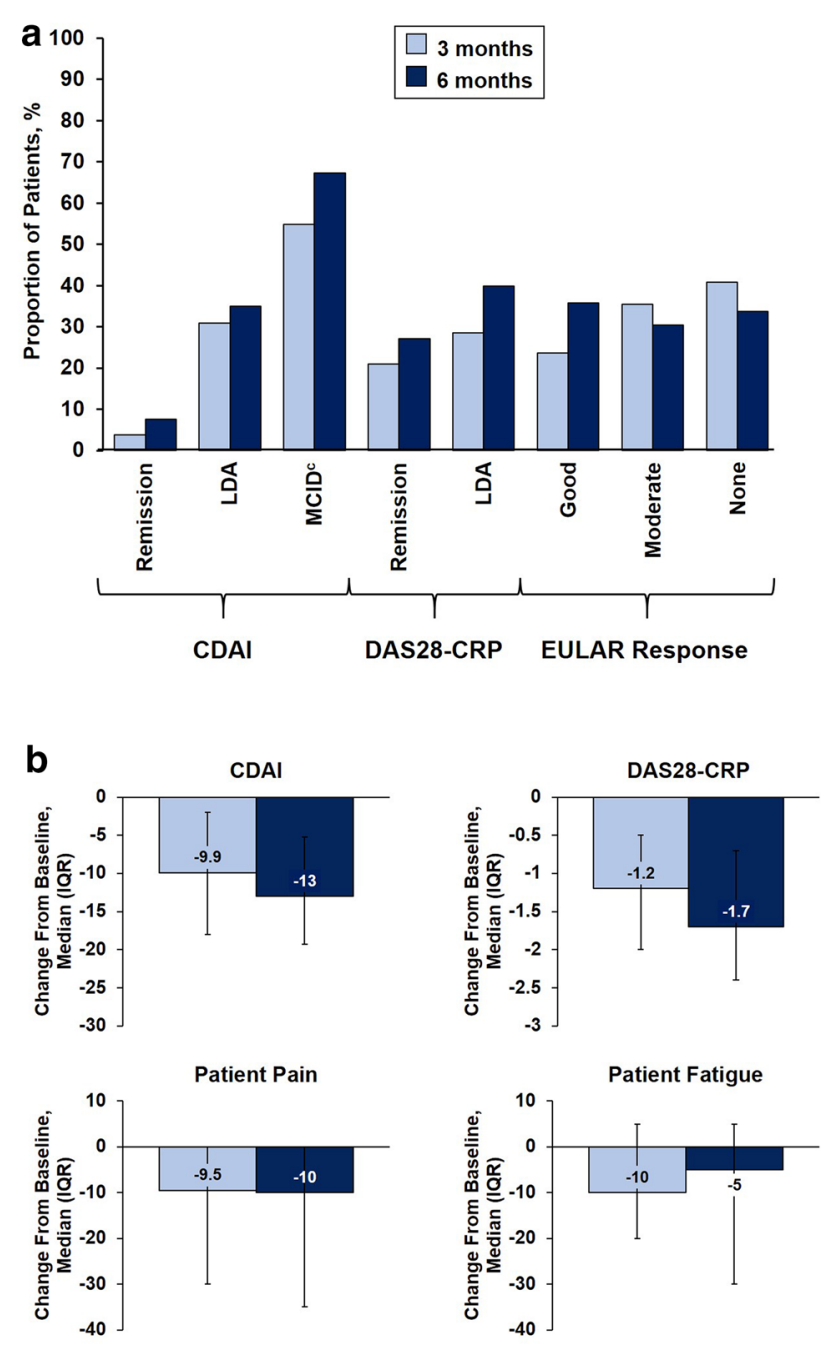

CRP, $\mathrm{mg} / \mathrm{L}$

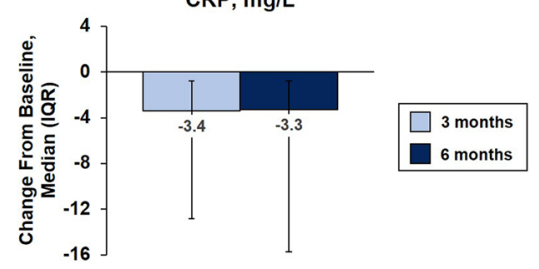

Fig. 3 Disease activity (a) and functional status and CRP (b) of patients in Group $2(n=110)$ at 3 and 6 months. Patients in Group 2 had their dose escalated from TCZ $4 \mathrm{mg} / \mathrm{kg}$ to TCZ $8 \mathrm{mg} / \mathrm{kg}$ prior to 3 months $(n=82)$ or at 3 months $(n=28)$. Median (IQR) decrease from baseline in mHAQ at 6 months was $0.0(-0.3$ to 0.0$)$ and $0.0(-0.4$ to 0.0 ) for patients in Group 1 and Group 2, respectively. MCID was defined as a decrease in CDAI of $\geq 6$ in patients with a baseline CDAI between 10 and 22 (moderate disease activity) and as a decrease in CDAI of $\geq 11$ in patients with a baseline CDAI $>22$ (high disease activity). CDAI Clinical Disease Activity Index, CRP, C-reactive protein, DAS28-CRP Disease Activity Score in 28 joints using CRP, EULAR European League Against Rheumatism, IQR Interquartile range, $L D A$ Low disease activity, $M C I D$ Minimal clinically important difference, $m H A Q$ Modified Health Assessment Questionnaire 
reduction [18]. Importantly, patients with worsened disease activity after dose reduction regained low disease activity after having their dose escalated back to $8 \mathrm{mg} / \mathrm{kg}$.

A limitation of this study was that the CERTAIN study design did not capture the exact timing of dose changes if they occurred between visits; only the medication dose and frequency were captured at the time of each CERTAIN follow-up visit. In these cases, CERTAIN summarized only the change in dose that happened between visits, not on the exact date. Thus, a change prior to the 3-month visit could have occurred very close to the baseline visit or very close to the 3-month visit. In the unlikely event that $>1$ change in dose occurred between visits, CERTAIN captured only the most recent change. As a result, a more detailed description of dose changes was not possible. In addition, observational data from registries are always subject to skepticism about generalizability of findings; however, CERTAIN was deployed in almost half of the Corrona participating practices with wide geographic and practice type distribution. Furthermore, the inclusion criteria of the study may add a further limit to the generalizability of our findings. In addition, it is important to note that this study did not aim to compare the effectiveness of the different escalation patterns and no adjusted effectiveness analyses took place; therefore, the overall favorable effect of the 2 dosing schemas can be attributed only to physicians responding to patients' disease activity appropriately and adjusting TCZ dose accordingly.

\section{CONCLUSIONS}

In conclusion, real-world data from the Corrona registry demonstrated that in this population of patients with significant disease burden and prior exposure to biologics, physicians escalated the dose of TCZ at varying frequencies, with the majority of patients having their dose escalated by or at 3 months. In this descriptive analysis the majority of patients in both TCZ dosing patterns achieved moderate or good EULAR response and experienced improvement in effectiveness outcomes, indicating that physicians adjusted TCZ dose appropriately, taking advantage of the option to tailor TCZ dose based on clinical response.

\section{ACKNOWLEDGMENTS}

The authors wish to thank Tmirah Haselkorn for her insightful and critical review of the manuscript. The Corrona CERTAIN study is sponsored by Corrona, LLC, with support from the Agency for Healthcare Research and Quality (R01HS018517). The majority of funding for the planning and implementation of CERTAIN was derived from Genentech, Inc, with additional support for substudies from Eli Lilly, Momenta Pharmaceuticals, and Pfizer. CERTAIN investigators also receive support from the National Institute of Health (JRC AR053351, JDG AR054 412). Funds to support this analysis and article processing charges for this manuscript were provided by Genentech, Inc, South San Francisco, CA, USA. All named authors meet the International Committee of Medical Journal Editors (ICMJE) criteria for authorship for this manuscript, take responsibility for the integrity of the work as a whole, and have given final approval to the version to be published. Support for third-party writing assistance, furnished by Eric Deutsch, PhD, and Ellen Mercado, PhD, of Health Interactions, was provided by F. Hoffmann-La Roche Ltd. This study was reported in ClinicalTrials.gov identifier, NCT01625650. 
Disclosures. Dimitrios A. Pappas is an employee of Corrona, LLC, and a paid instructor for Novartis. Ani John is an employee of Genentech, Inc. Jeffrey R. Curtis has received consulting fees, honoraria, and research grants from AbbVie, Amgen, BMS, Corrona, Crescendo, Janssen, Pfizer, Roche/ Genentech, and UCB. George W. Reed is an employee of Corrona, LLC. Chitra Karki is an employee of Corrona, LLC. Robert Magner is an employee of the University of Massachusetts Medical School. Joel M. Kremer is a shareholder and an employee of Corrona, LLC, and has received consulting fees and research support from Genentech, Inc. Ashwini Shewade is an employee of Genentech, Inc. Jeffrey D. Greenberg is a shareholder and an employee of Corrona, LLC, and a consultant for AstraZeneca, Celgene, Novartis, and Pfizer.

Compliance with Ethics Guidelines. All procedures followed were in accordance with the ethical standards of the responsible committee on human experimentation (institutional and national) and with the Helsinki Declaration of 1964, as revised in 2013. Informed consent was obtained from all patients for being included in the study.

Open Access. This article is distributed under the terms of the Creative Commons AttributionNonCommercial 4.0 International License (http://creativecommons.org/licenses/by-nc/4. $0 /$ ), which permits any noncommercial use, distribution, and reproduction in any medium, provided you give appropriate credit to the original author(s) and the source, provide a link to the Creative Commons license, and indicate if changes were made.

\section{REFERENCES}

1. Smolen JS, Landewe R, Breedveld FC, et al. EULAR recommendations for the management of rheumatoid arthritis with synthetic and biological disease-modifying antirheumatic drugs: 2013 update. Ann Rheum Dis. 2014;73:492-509.

2. Singh JA, Furst DE, Bharat A, et al. 2012 update of the 2008 American College of Rheumatology recommendations for the use of disease-modifying antirheumatic drugs and biologic agents in the treatment of rheumatoid arthritis. Arthritis Care Res (Hoboken). 2012;64:625-39.

3. Actemra (tocilizumab) [package insert]. South San Francisco: Genentech, Inc; 2013.

4. Balsa A, Tovar Beltran JV, Caliz Caliz R, et al. Patterns of use and dosing of tocilizumab in the treatment of patients with rheumatoid arthritis in routine clinical practice: the ACT-LIFE study. Rheumatol Int. 2015;35:1525-34.

5. Dougados M, Kissel K, Sheeran T, et al. Adding tocilizumab or switching to tocilizumab monotherapy in methotrexate inadequate responders: 24-week symptomatic and structural results of a 2-year randomised controlled strategy trial in rheumatoid arthritis (ACT-RAY). Ann Rheum Dis. 2013;72:43-50.

6. Jones G, Sebba A, Gu J, et al. Comparison of tocilizumab monotherapy versus methotrexate monotherapy in patients with moderate to severe rheumatoid arthritis: the AMBITION study. Ann Rheum Dis. 2010;69:88-96.

7. Burmester GR,W., van Vollenhoven R, Kay J, et al. Tocilizumab (TCZ) in combination and monotherapy versus methotrexate (MTX) in MTX-naive patients (PTS) with early rheumatoid arthritis (RA): clinical and radiographic outcomes from a randomised, placebo-controlled trial. Ann Rheum Dis. 2013;72 [abstract OP0041].

8. Patel AM, Moreland LW. Interleukin-6 inhibition for treatment of rheumatoid arthritis: a review of tocilizumab therapy. Drug Des Devel Ther. 2010;4:263-78.

9. Smolen JS, Beaulieu A, Rubbert-Roth A, et al. Effect of interleukin-6 receptor inhibition with tocilizumab in patients with rheumatoid arthritis (OPTION study): a double-blind, placebo-controlled, randomised trial. Lancet. 2008;371:987-97. 
10. Emery P, Keystone E, Tony HP, et al. IL-6 receptor inhibition with tocilizumab improves treatment outcomes in patients with rheumatoid arthritis refractory to anti-tumour necrosis factor biologicals: results from a 24-week multicentre randomised placebo-controlled trial. Ann Rheum Dis. 2008;67:1516-23.

11. Fleischmann RM, Halland AM, Brzosko M, et al. Tocilizumab inhibits structural joint damage and improves physical function in patients with rheumatoid arthritis and inadequate responses to methotrexate: LITHE study 2-year results. J Rheumatol. 2013;40:113-26.

12. Nishimoto $\mathrm{N}$, Yoshizaki $\mathrm{K}$, Miyasaka $\mathrm{N}$, et al. Treatment of rheumatoid arthritis with humanized anti-interleukin- 6 receptor antibody: a multicenter, double-blind, placebo-controlled trial. Arthritis Rheum. 2004;50:1761-9.

13. Maini RN, Taylor PC, Szechinski J, et al. Double-blind randomized controlled clinical trial of the interleukin-6 receptor antagonist, tocilizumab, in European patients with rheumatoid arthritis who had an incomplete response to methotrexate. Arthritis Rheum. 2006;54:2817-29.
14. Kremer JM. The CORRONA database. Autoimmun Rev. 2006;5:46-54.

15. Pappas DA, Kremer JM, Reed G, Greenberg JD, Curtis JR. Design characteristics of the CORRONA CERTAIN study: a comparative effectiveness study of biologic agents for rheumatoid arthritis patients. BMC Musculoskelet Disord. 2014;15:113.

16. Curtis JR, Yang S, Chen L, et al. Determining the minimally important difference in the clinical disease activity index for improvement and worsening in early rheumatoid arthritis. Arthritis Care Res (Hoboken). 2015;67:1345-53.

17. Genovese MC, McKay JD, Nasonov EL, et al. Interleukin-6 receptor inhibition with tocilizumab reduces disease activity in rheumatoid arthritis with inadequate response to disease-modifying antirheumatic drugs: the tocilizumab in combination with traditional disease-modifying antirheumatic drug therapy study. Arthritis Rheum. 2008;58:2968-80.

18. van Herwaarden N, Herfkens-Hol S, van der Maas A, et al. Dose reduction of tocilizumab in rheumatoid arthritis patients with low disease activity. Clin Exp Rheumatol. 2014;32:390-4. 